\title{
Clinical characteristics of colitis induced by taxane-based chemotherapy
}

\author{
Ellie Chen a*, Hamzah Abu-Sbeih ${ }^{b *}$, Selvi Thirumurthi ${ }^{b}$, Niharika Mallepallya , Shruti Khuranac, \\ Dongguang Weid ${ }^{\text {, Mehmet Altann }}$, Van K. Morris', Dongfeng Tan ${ }^{d}$, Carlos H. Barcenas ${ }^{g}$, Yinghong Wang ${ }^{b}$
}

Baylor College of Medicine; The University of Texas MD Anderson Cancer Center; McGovern Medical School, The University of Texas Health Science Center, Houston, Texas, USA

\section{Abstract}

Department of a Medicine, Baylor College of Medicine (Ellie Chen, Niharika Mallepally); ${ }^{b}$ Gastroenterology, Hepatology and Nutrition, The University of Texas MD Anderson Cancer Center (Hamzah Abu-Sbeih, Selvi Thirumurthi, Yinghong Wang); 'Internal Medicine, McGovern Medical School, The University of Texas Health Science Center (Shruti

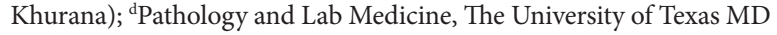
Anderson Cancer Center (Dongguang Wei, Dongfeng Tan); ${ }^{\mathrm{e} T h o r a c i c /}$ Head and Neck Medical Oncology, The University of Texas MD Anderson, Cancer Center (Mehmet Altan); ${ }^{\mathrm{f}}$ Gastrointestinal Medical Oncology, The University of Texas MD Anderson Cancer Center (Van K. Morris); ${ }^{\mathrm{B} B r e a s t}$ Medical Oncology, The University of Texas MD Anderson Cancer Center (Carlos H. Barcenas), Houston, Texas, USA

${ }^{*}$ Co-first authors

Conflict of Interest: None

Correspondence to: Yinghong Wang, MD, PhD, Department of Gastroenterology, Hepatology and Nutrition, The University of Texas MD Anderson Cancer Center, 1515 Holcombe Blvd., Unit 1466, Houston, TX 77030, USA, e-mail: ywang59@mdanderson.org

Received 17 July 2019; accepted 7 October 2019; published online 21 November 2019

DOI: https://doi.org/10.20524/aog.2019.0431

\section{Introduction}

Taxanes are a widely used class of potent chemotherapy agents for breast, lung, head and neck, pancreatic, esophageal, gastric, anal, and ovarian cancers [1-7]. The first taxane, named paclitaxel, was purified from the bark of the pacific yew tree, Taxus brevifolia, as a part of a large plant-screening program led by the US National Cancer Institute and Department of Agriculture [8-10].

Paclitaxel's mechanism of cytotoxicity is unique, as it promotes microtubule polymer formation in cells, thus stabilizing the microtubule polymer structure and inhibiting microtubule depolymerization back to tubulin. This process depletes free tubulin and creates arrays of disorganized microtubules inefficient for cell replication, thereby blocking mitosis $[11,12]$. Because paclitaxel arrests mitosis, the toxic effects of paclitaxel are most evident in tissues with rapid cell turnover, including hematopoietic, lymphatic, gastrointestinal (GI), and reproductive tissues, as well as tissue affected by alopecia. Studies have identified neutropenia, neuropathy, 
mucositis, asymptomatic bradycardia, myalgia, arthralgia and diarrhea as major side effects of paclitaxel therapy [13].

Only a limited number of studies have investigated the GI effects of taxanes. These could present as nausea, vomiting, and diarrhea $[13,14]$. A few case reports showed that taxane-induced colitis can even lead to colonic perforation, requiring surgery, and has histological features similar to ischemic colitis, characterized by a thinned attenuated surface epithelium, increased fibrosis, neutrophil infiltration and focal hemorrhage [15-17]. The largest study to date was conducted at MD Anderson in 2004 and included 14 patients diagnosed with colitis while receiving taxane therapy. During the study period of 2 years, the incidence of colitis in patients who received docetaxel was $1.9 \%$, while in those treated with paclitaxel it was $0.5 \%$. Colitis was defined as symptoms of acute abdominal pain, direct or rebound tenderness with associated fever, neutropenia, and/or diarrhea. Colonoscopy was performed in 2 patients and showed features that raised concern for ischemic colitis. All patients received supportive care, including antibiotics, fluid resuscitation and monitoring. However, no clear conclusion was derived from this study as to whether these treatments helped to alleviate symptoms. One patient died from sepsis and 2 had bowel perforation requiring surgery, which demonstrated that taxane-induced colitis could be a serious side effect in the treatment of breast cancer [18]. Despite these descriptive studies, our knowledge of the clinical features, endoscopic/histologic findings, treatments and outcomes of taxane-induced colitis is still limited.

Despite the low incidence $(0.5-1.9 \%)$ of taxane-induced colitis, it remains a significant clinical problem. Yet, to date, no existing guidelines describe the clinical course and management recommendations for taxane-induced colitis. For clinicians (including gastroenterologists) caring for patients with taxaneinduced colitis, a better understanding of this disease is needed to inform their management. The purpose of this study was to address this gap in knowledge by using our large database at a tertiary cancer center to describe the clinical, endoscopic and histological features of taxane-induced colitis.

\section{Patients and methods}

\section{Study design and population}

This was a retrospective cohort study of adult patients with any type of cancer who received taxane-based chemotherapy at the University of Texas MD Anderson Cancer Center between 2000 and 2018. After institutional review board approval, we extracted data from electronic medical and pharmacy records to screen for all adult cancer patients at our center who received taxane-based chemotherapy and also underwent a lower GI endoscopy evaluation for GI symptoms or anemia during this time. Patients were included if they received paclitaxel, docetaxel or nab-paclitaxel, either as single agents or as part of a multi-agent therapy regimen. Patients diagnosed with infectious colitis (confirmed by laboratory test), graft-versus- host disease (confirmed by pathology assessment), or radiation proctocolitis (confirmed by colonoscopy and pathologic assessment) were not included in this study.

We included patients who had undergone either colonoscopy or flexible sigmoidoscopy with endoscopic and/or histologic findings suggestive of colitis related to taxane treatment (Fig. 1). Patients were excluded if their histologic examination revealed no colitis or if the endoscopic evaluation was performed more than 1 year after the last dose of taxane treatment. Patients were also excluded if symptoms or colonoscopy findings suggestive of colitis were present prior to the initiation of taxane therapy. Patients with a diagnosis of underlying ulcerative colitis or Crohn's disease were also excluded from this study.

\section{Oncologic data and cancer treatment course}

After the study cohort was identified, data pertaining to demographics, comorbidities, oncologic history, taxane regimen, taxane treatment-related non-GI adverse effects and clinical presentation of colitis were collected from their electronic medical charts. Patients' demographics included age, sex, and race/ethnicity. Clinical history variables consisted of smoking, non-steroidal anti-inflammatory drug (NSAID) use, history of inflammatory bowel disease, comorbidities (according to the Charlson comorbidity index) [19], cancer type and stage, GI tract involvement by cancer, and radiation to the abdomen. We ascertained details of patients' most recent taxane regimen, including the taxane agent, date of initiation, dose, frequency, date of last dose, reason for discontinuation, and concurrent chemotherapy agents.

\section{Clinical features of $\mathrm{Gl}$ adverse events}

We identified the clinical features of taxane-induced colitis, including onset, duration, symptoms, and initial and peakgrades of diarrhea or colitis, based on the National Cancer Institute's Common Terminology Criteria for Adverse Events, version 5.0 [20]. Colitis was defined as abrupt onset, when the highest grade of colitis occurred at the time of initial presentation, or gradual onset, when a milder grade of colitis occurred at the time of initial presentation then progressed to a more severe grade. Symptoms of colitis included abdominal pain, abdominal distension and blood or mucus with stool. We also noted colitis treatments received and their duration, whether each patient was hospitalized for colitis, and complications from colitis. We gathered laboratory results regarding patients' nadir absolute neutrophil count (ANC) within 1 week of colitis onset, stool cultures, and lactoferrin and calprotectin levels. The level of ANC at the time of an event was collected to clarify other differential diagnoses, e.g. neutropenic colitis. We also evaluated any computed tomography (CT) studies of the abdomen and pelvis obtained 1 week either before or after endoscopy. Characteristics and location of colitis on CT scans, such as wall thickening, pericolic fat stranding, mucosal enhancement, and bowel loop dilation, were recorded. 


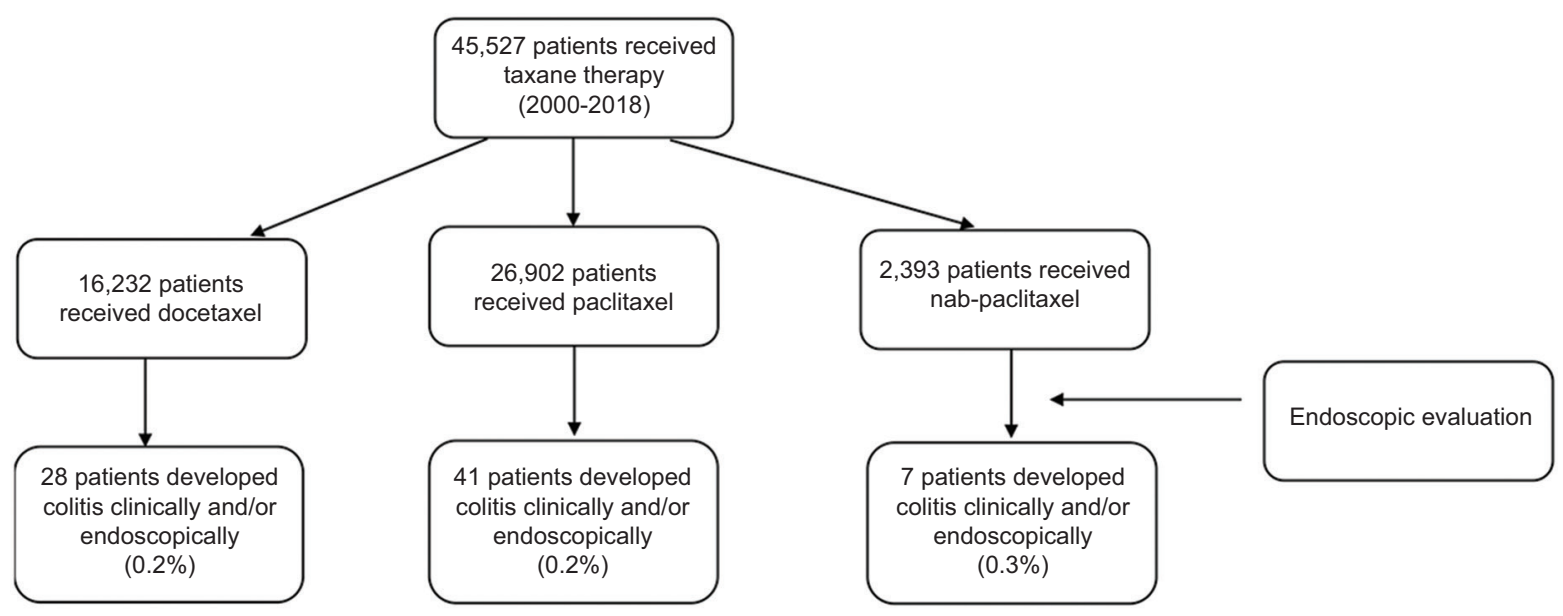

Figure 1 Flowchart of included patients

\section{Endoscopic and histologic features}

Patients' endoscopy reports were reviewed. A spectrum of endoscopic findings of colitis was described, from the presence of mucosal ulcerations, to nonulcerative inflammation (erythema, exudate, loss of vascular pattern, edema, erosions), or a normal appearance (Fig. 2). The distribution of colitis was classified as left colon only, right colon only, both left and right colon, or ileum. We used extensive colitis to describe inflammation in more than 1 segment of colon. The pattern of inflammation was categorized as diffuse, patchy or segmental. Pathology reports for each colonoscopy were reviewed as well. Inflammation patterns were categorized as active, chronic or lymphocytic (Fig. 3). Features of active inflammation included neutrophilic or eosinophilic infiltrate, cryptitis and crypt abscess. Features of chronicity were basal lymphocytic infiltrate, cryptic architecture distortion, apoptosis and Paneth cell metaplasia. Lymphocytic colitis was reported separately as showing the classical histological features of increased intraepithelial lymphocyte infiltration.

\section{Treatment and outcomes of toxic Gl effects}

For all patients who received taxane therapy and developed colitis, we noted whether or not they received treatment for their colitis symptoms. If patients received colitis treatment, the type and duration of such treatment, including start and end dates, were recorded. The antibiotic treatment recorded in our cohort was exclusively for empirical purpose, as we excluded patients with a confirmed GI infection. The outcomes of colitis were defined as duration of colitis symptoms, requirement of hospitalization or intensive care unit (ICU) admission, duration of hospitalization, and recurrence of GI symptoms. Complications of colitis, such as colonic perforations, were also noted. Colitis resolution was defined as the return of clinical symptoms to baseline clinical presentation before the colitis event.

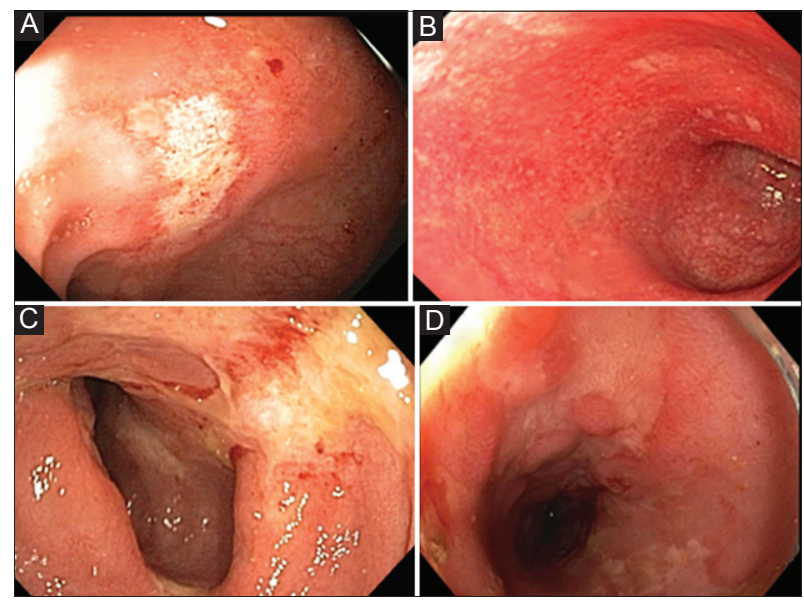

Figure 2 Endoscopic features of colitis. There is a spectrum of inflammatory presentations on the endoscopy evaluation. (A) Patchy inflammation with superficial ulceration; (B) Diffuse erythema and loss of vascular pattern; (C, D) Patchy inflammation with large deep ulceration

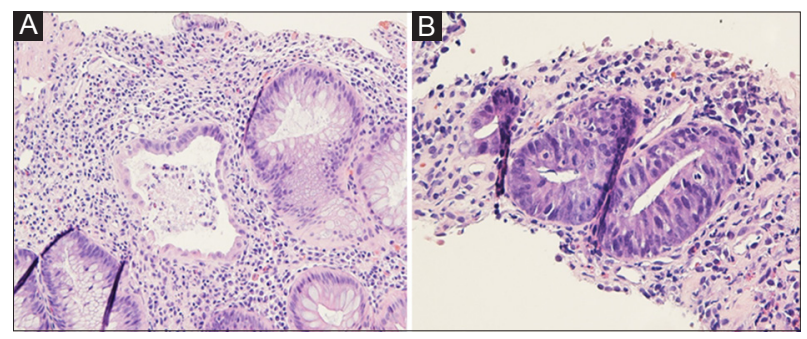

Figure 3 Pathological features of colonic inflammation. Cryptitis, crypt distortion, crypt abscesses. (A) H\&E 10X; (B) H\&E, 20X

\section{Statistical analysis}

We used SAS version 9.4 (SAS Institute, Cary, NC) and SPSS version 24.0 (IBM Corporation, Armonk, NY) for our statistical analysis. Each continuous variable distribution was summarized using medians and interquartile ranges. Distributions of categorical variables were summarized using 
Table 1 Patients' characteristics

\begin{tabular}{|c|c|}
\hline Covariate & Total $n=76$ \\
\hline Age, median years (IQR) & $59(51-66)$ \\
\hline Male, $n(\%)$ & $32(42)$ \\
\hline $\begin{array}{l}\text { Race, } n(\%) \\
\text { White } \\
\text { Black } \\
\text { Other }\end{array}$ & $\begin{array}{c}59(78) \\
12(16) \\
5(7)\end{array}$ \\
\hline NSAID use, $n(\%)$ & $41(54)$ \\
\hline Smoking, $n(\%)$ & $37(49)$ \\
\hline Comorbidities, $n(\%)$ & $50(66)$ \\
\hline ANC at time of diarrhea, median $\mathrm{K} / \mathrm{mm}^{3}$ (IQR) & $3.0(1.3-4.6)$ \\
\hline $\begin{array}{l}\text { Primary malignancy, } n(\%) \\
\text { Breast } \\
\text { Head, neck and chest } \\
\text { Gastrointestinal and hepatobiliary } \\
\text { Genitourinary } \\
\text { Melanoma } \\
\text { Other }\end{array}$ & $\begin{array}{l}26(34) \\
23(30) \\
11(15) \\
9(12) \\
4(5) \\
3(4)\end{array}$ \\
\hline Duration of taxane treatment, median days (IQR) & $59(21-91)$ \\
\hline $\begin{array}{l}\text { Time from taxane therapy to colitis onset, median } \\
\text { days (IQR) }\end{array}$ & $31(8-112)$ \\
\hline $\begin{array}{l}\text { Type of taxane therapy, } n(\%) \\
\text { Paclitaxel } \\
\text { Docetaxel } \\
\text { Nab-paclitaxel }\end{array}$ & $\begin{array}{l}41(54) \\
28(37) \\
7(9)\end{array}$ \\
\hline Regimen containing platinum therapy, $n(\%)$ & $44(58)$ \\
\hline Adjuvant radiotherapy, $n(\%)$ & $33(43)$ \\
\hline $\begin{array}{l}\text { Reason to stop taxane treatment, } n(\%) \\
\text { Colitis } \\
\text { Cancer progression } \\
\text { Other adverse events } \\
\text { Other }\end{array}$ & $\begin{array}{l}12(16) \\
16(21) \\
12(16) \\
35(46)\end{array}$ \\
\hline $\begin{array}{l}\text { Symptom onset, } n(\%) \\
\text { Gradual } \\
\text { Abrupt }\end{array}$ & $\begin{array}{l}61(80) \\
15(20)\end{array}$ \\
\hline Duration of symptoms, median days (IQR) & $30(12-60)$ \\
\hline $\begin{array}{l}\text { Duration from symptom onset to treatment, } \\
\text { median days (IQR) }\end{array}$ & $6(1-15)$ \\
\hline Hospitalization, $n(\%)$ & $35(46)$ \\
\hline ICU admission, $n(\%)$ & $7(9)$ \\
\hline $\begin{array}{l}\text { Had CT imaging evaluation, } n(\%) \\
\text { Abnormal findings }\end{array}$ & $\begin{array}{l}25(33) \\
18(72)\end{array}$ \\
\hline $\begin{array}{l}\text { GI symptom treatment, } n(\%) \\
\text { Immunosuppressants } \\
\text { Systemic corticosteroid } \\
\text { Topical corticosteroid } \\
\text { Antibiotics } \\
\text { Antimotility agents } \\
\text { IV fluids } \\
\text { Octreotide or somatostatin }\end{array}$ & $\begin{array}{c}50(66) \\
8(11) \\
5(7) \\
3(4) \\
17(22) \\
18(24) \\
35(46) \\
2(3)\end{array}$ \\
\hline $\begin{array}{l}\text { Duration of overall symptom treatment, median } \\
\text { days (IQR) }\end{array}$ & $14(7-32)$ \\
\hline
\end{tabular}

(Contd...)
Table 1 (Continued)

\begin{tabular}{lc} 
Covariate & Total $n=76$ \\
\hline $\begin{array}{l}\text { Duration of antibiotic treatment, median days } \\
\text { (IQR) }\end{array}$ & $12(10-17)$ \\
Perforation, $n(\%)$ & $1(1)$ \\
Restart taxane therapy after colitis, $n(\%)$ & $19(25)$ \\
Median follow-up duration, months (IQR) & $20(6-35)$ \\
Recurrent GI symptoms, $n(\%)$ & $7(9)$
\end{tabular}

ANC, absolute neutrophil count; CT, computed tomography; GI, gastrointestinal; ICU, intensive care unit; $I Q R$, interquartile range; $I V$, intravenous; NSAID, nonsteroidal anti-inflammatory drug

frequencies and percentages. Continuous variables were compared using the Wilcoxon rank sum or Kruskal-Wallis test for comparisons among groups. The Fisher exact test or chi-square test was used to evaluate associations between 2 categorical variables. All statistical evaluations were 2 -sided. $P$ values of 0.05 or less were considered statistically significant.

\section{Results}

\section{Patient characteristics}

Of the 45,527 patients who received taxane-based therapy during the study period, 76 were included in our analyses (Fig. 1). The median age was 59 years and $58 \%$ were female (Table 1). The majority of patients were Caucasian $(n=59,78 \%)$. About half of our cohort were smokers $(n=37,49 \%)$, half used NSAIDs $(n=41,54 \%)$, and more than half had comorbidities $(n=50,66 \%)$. Breast cancer was the most common cancer type $(n=26,34 \%)$, while thoracic and head and neck cancers were the second most common $(n=23,30 \%)$. Fifty-four percent of patients received paclitaxel, 37\% received docetaxel and 9\% received nab-paclitaxel. More than half the patients received a regimen containing concurrent platinum therapy $(n=44,58 \%)$, and less than half received adjuvant radiotherapy $(n=33,43 \%)$.

\section{Clinical features}

The median duration of taxane therapy was 59 days, with a wide variation of infusion interval between weekly and bimonthly, and a median cycle number of 4 . The median time from the start of taxane therapy to colitis onset was 31 days (Table 1). Chemotherapy was discontinued because of cancer progression in $21 \%$ of patients, colitis in $16 \%$ and other adverse events in $16 \%$; chemotherapy was not interrupted in the other patients. The onset of colitis symptoms was usually gradual $(\mathrm{n}=61,80 \%)$, and the median duration of symptoms was 30 days. The median ANC at time of colitis onset was $3.0 \mathrm{~K} / \mathrm{mm}^{3}$, well above the level of neutropenia.

Of our patients, $88 \%$ were symptomatic, while $12 \%$ were clinically asymptomatic but had anemia. The presence of symptoms was not associated with the type of taxane 
chemotherapy received. Of the common symptoms, diarrhea and vomiting were most likely to be treated $(\mathrm{P}<0.001$ and $\mathrm{P}=0.044$, respectively), especially higher grades of diarrhea ( $\mathrm{P}=0.036$; Table 2).

The clinical presentation also differed according to the type of chemotherapy received. The onset of symptoms was earliest for nab-paclitaxel and latest for paclitaxel $(\mathrm{P}=0.003)$; however, colitis symptoms were not different among the different taxanes. Nab-paclitaxel therapy was associated with hospitalization $(\mathrm{P}=0.005)$. Both docetaxel- and nab-paclitaxel-associated colitis were more likely than paclitaxel-associated colitis to be treated with intravenous fluid ( $\mathrm{P}=0.025$; Table 3$)$. On the other hand, the clinical characteristics of colitis, treatment requirement and outcomes were similar between the patients who received taxane monotherapy versus taxane with adjuvant platinum-based therapy (Supplementary Table 1).

\section{Endoscopic and histologic features}

All 76 patients underwent a colonoscopy for GI symptoms or anemia, and all had abnormal endoscopic or histologic features (Fig. 2, 3). Symptoms, type of chemotherapy received, and whether or not patients received treatment for colitis were not associated with endoscopic features such as normal appearance, ulceration, or nonulcerative inflammation (Tables 2, 3). Patients with lymphocytic colitis on histology had the whole spectrum of endoscopic presentations. Of symptomatic patients, $27 \%$ had mucosal ulceration, $42 \%$ had nonulcerative inflammation, and $31 \%$ had normal colonoscopy findings. Compared with asymptomatic patients, symptomatic patients had a different pattern of inflammation $(\mathrm{P}=0.019)$ but similar locations of inflammation on endoscopy.

Histologic features were similar between symptomatic and asymptomatic patients, regardless of the treatment requirement for GI symptoms and the type of taxane (Tables 2, 3). Endoscopic features were similar between patients who received antibiotics and those who did not. However, endoscopic features differed between patients who received intravenous fluids and those who did not $(\mathrm{P}=0.044)$ (Table 4). Among patients who received intravenous fluids, 50\% had mucosal ulceration, 36\% had nonulcerative inflammation, and $14 \%$ had normal endoscopic findings. Among patients who did not receive intravenous fluids, ulceration was less prevalent (19\%) than nonulcerative inflammation (44\%).

\section{Treatment and outcomes}

Fifty patients (66\%) were treated for colitis symptoms; $46 \%$ received fluids, $24 \%$ received antimotility agents, $22 \%$ received antibiotics, $11 \%$ received immunosuppressants (systemic steroid in 5, and topical steroid in 3), and 3\% received octreotide or somatostatin. Twenty-six patients $(34 \%)$ did not receive any medical treatment. Treatment was started an average of 6 days from symptom onset, with an average duration of 14

Table 2 Patient characteristics stratified by colitis treatment

\begin{tabular}{|c|c|c|c|}
\hline Covariate & Treatment $^{\mathrm{a}} n=50$ & No treatment $n=26$ & $P$ \\
\hline $\begin{array}{l}\text { Type of taxane therapy, } n(\%) \\
\text { Paclitaxel } \\
\text { Docetaxel } \\
\text { Nab-paclitaxel }\end{array}$ & $\begin{array}{l}26(52) \\
19(38) \\
5(10)\end{array}$ & $\begin{array}{c}15(58) \\
9(35) \\
2(8)\end{array}$ & 0.880 \\
\hline $\begin{array}{l}\text { Clinical symptoms, } n(\%) \\
\text { Diarrhea } \\
\text { Abdominal pain } \\
\text { Blood or mucous } \\
\text { Vomiting }\end{array}$ & $\begin{array}{l}42(84) \\
23(46) \\
28(56) \\
14(28)\end{array}$ & $\begin{array}{c}11(42) \\
7(27) \\
11(42) \\
2(8)\end{array}$ & $\begin{array}{c}<0.001 \\
0.140 \\
0.335 \\
0.044\end{array}$ \\
\hline $\begin{array}{l}\text { Peak grade of diarrhea, } n(\%)^{\mathrm{b}} \\
1 \\
2 \\
3\end{array}$ & $\begin{array}{l}12(29) \\
16(38) \\
14(33)\end{array}$ & $\begin{array}{l}7(64) \\
4(36) \\
0(0)\end{array}$ & 0.036 \\
\hline Duration of symptoms, median days (IQR) & $30(14-60)$ & $30(3-105)$ & 0.975 \\
\hline CT scan imaging abnormality, $n(\%)^{c}$ & $15(83)$ & $3(43)$ & 0.066 \\
\hline Endoscopic abnormality, $n(\%)$ & $33(66)$ & $18(69)$ & 1.000 \\
\hline Active inflammation on histology, $n(\%)$ & $43(86)$ & $20(76)$ & 0.295 \\
\hline Received taxane after GI toxic effects, $n(\%)$ & $11(22)$ & $8(31)$ & 0.416 \\
\hline Recurrent GI symptoms, $n(\%)$ & $5(10)$ & $2(8)$ & 1.000 \\
\hline
\end{tabular}

\footnotetext{
aTreatment of GI toxic effects included IV fluids, antibiotic, immunosuppressants, and/or antimotility agents

${ }^{\mathrm{b}}$ Available for 53 patients: 42 who received treatment for colitis and 11 who did not

cAvailable for 25 patients: 18 who received treatment for colitis and 7 who did not

GI, gastrointestinal; $I V$, intravenous; IQR, interquartile range
} 
Table 3 Patient characteristics stratified by taxane therapy type

\begin{tabular}{|c|c|c|c|c|}
\hline Covariate & Paclitaxel $n=41$ & Docetaxel $n=28$ & Nab-paclitaxel $n=7$ & $P$ \\
\hline Duration from taxane treatment to onset, median days (IQR) & $58(21-158)$ & $13(7-47)$ & $4(2-33)$ & 0.003 \\
\hline $\begin{array}{l}\text { Peak grade of diarrhea, } n(\%)^{\mathrm{a}} \\
1 \\
2 \\
3\end{array}$ & $\begin{array}{c}13(43) \\
13(43) \\
4(13)\end{array}$ & $\begin{array}{l}5(28) \\
6(33) \\
7(39)\end{array}$ & $\begin{array}{l}1(20) \\
1(20) \\
3(60)\end{array}$ & 0.215 \\
\hline Duration of symptoms, median days (IQR) & $35(18-90)$ & $22(8-56)$ & $13(8-60)$ & 0.345 \\
\hline Hospitalization, $n(\%)$ & $14(34)$ & $14(50)$ & $7(100)$ & 0.005 \\
\hline ICU admission, $n(\%)$ & $4(10)$ & $3(11)$ & $0(0)$ & 0.670 \\
\hline Duration of hospitalization, median days (IQR) & $5(3-18)$ & $8(5-15)$ & $8(4-11)$ & 0.757 \\
\hline $\begin{array}{l}\text { Endoscopic presentation, } n(\%) \\
\text { Ulcer } \\
\text { Nonulcerative inflammation } \\
\text { Normal }\end{array}$ & $\begin{array}{l}7(17) \\
17(42) \\
17(42)\end{array}$ & $\begin{array}{c}8(29) \\
13(46) \\
7(25)\end{array}$ & $\begin{array}{l}4(57) \\
2(29) \\
1(14)\end{array}$ & 0.154 \\
\hline Active inflammation on histology, $n(\%)$ & $37(90)$ & $22(79)$ & $4(57)$ & 0.151 \\
\hline $\begin{array}{l}\text { Treatment, } n(\%) \\
\text { Immunosuppressants } \\
\text { Antibiotic } \\
\text { Antimotility agents } \\
\text { IV fluid } \\
\text { Octreotide and somatostatin }\end{array}$ & $\begin{array}{l}26(63) \\
6(15) \\
6(15) \\
10(24) \\
3(7) \\
0(0)\end{array}$ & $\begin{array}{l}19(68) \\
1(4) \\
10(36) \\
7(25) \\
9(32) \\
1(4)\end{array}$ & $\begin{array}{l}5(71) \\
1(14) \\
1(14) \\
1(14) \\
2(29) \\
1(14)\end{array}$ & $\begin{array}{l}0.880 \\
0.320 \\
0.103 \\
0.827 \\
0.025 \\
0.086\end{array}$ \\
\hline Restart taxane after GI toxic effects, $n(\%)$ & $8(20)$ & $8(29)$ & $3(43)$ & 0.361 \\
\hline Recurrent GI symptoms, $n(\%)$ & $4(10)$ & $2(7)$ & $1(14)$ & 0.830 \\
\hline
\end{tabular}

days. About half (46\%) of the patients were hospitalized for their colitis symptoms, but only a minority (9\%) of patients required ICU admission. Among the 35 hospitalized patients, 18 received: intravenous fluids $(n=4)$, or antibiotics $(n=5)$, or both $(n=9)$. Three patients also received an antimotility agent and/or immunosuppressant. One patient whose course was complicated by colitis-related colonic perforation died soon after transition to hospice; this patient was receiving nab-paclitaxel and gemcitabine. Taxane therapy was restarted in $25 \%$ of patients after colitis onset, and colitis symptoms recurred in $9 \%$. Patients who received treatment for colitis had the same rate of recurrent GI symptoms as patients who did not receive treatment. Smoking and NSAID use did not appear to affect the endoscopic findings and clinical outcomes, except that NSAID use was associated with a higher hospitalization requirement $(\mathrm{P}=0.006)$ (Supplementary Table 2).

Patients with diarrhea, abdominal pain, or vomiting were more likely to receive antibiotic treatment $(\mathrm{P}=0.002,0.004$, and $<0.001$ respectively; Table 4 ). These were administered either as monotherapy or combination therapy, with a median duration of 12 days (Table 1 and Supplementary Table 3). Patients with abdominal pain or vomiting were more likely to be treated with intravenous fluids $(\mathrm{P}=0.013$ and $<0.001$ respectively) than patients without these symptoms. Hospitalized patients were also more likely to be treated with antibiotics and intravenous fluids ( $\mathrm{P}=0.006$ and $<0.001$ respectively) than were patients who did not require hospitalization. In our cohort, 9 patients received both antibiotics and intravenous fluids. Patients who received antibiotics had a shorter duration of symptoms, with a mean duration of 24 days, while those who did not receive antibiotics had a mean duration of 63 days $(\mathrm{P}=0.025)$. Likewise, patients who received intravenous fluids had a shorter duration of symptoms compared with those who did not $(\mathrm{P}=0.037)$. More patients who received antibiotics for taxane-induced colitis were able to resume taxane therapy after resolution of colitis, but this difference was not significant $(\mathrm{P}=0.080)$.

\section{Discussion}

To our knowledge, this cohort of 76 patients represents the largest study to date to evaluate the characteristics of taxaneinduced colitis. In this study, taxane-induced colitis did not occur immediately after chemotherapy induction, but rather gradually and slowly; the average time from taxane therapy to colitis onset was around 1 month. Colitis can have a wide array of symptoms, most commonly diarrhea or blood in stool, and less commonly abdominal pain and nausea. Most patients received treatment for colitis symptoms; these treatments included intravenous fluids, antimotility agents, antibiotics, immunosuppressants, and octreotide and somatostatin. Treatment with intravenous fluids and antibiotics reduced the duration of symptoms. However, antibiotics and intravenous 
Table 4 Patient characteristics stratified by antibiotic and IV fluid treatments for GI symptoms

\begin{tabular}{|c|c|c|c|c|c|c|}
\hline Covariate & $\begin{array}{c}\text { Antibiotic } \\
n=17\end{array}$ & $\begin{array}{c}\text { No Antibiotic } \\
n=59\end{array}$ & $P$ & $\begin{array}{l}\text { IV Fluid } \\
n=14\end{array}$ & $\begin{array}{c}\text { No IV Fluid } \\
\quad n=62\end{array}$ & $P$ \\
\hline $\begin{array}{l}\text { Type of taxane therapy, } n(\%) \\
\text { Paclitaxel } \\
\text { Docetaxel } \\
\text { Nab-paclitaxel }\end{array}$ & $\begin{array}{c}6(35) \\
10(59) \\
1(6)\end{array}$ & $\begin{array}{l}35(59) \\
18(31) \\
6(10)\end{array}$ & 0.103 & $\begin{array}{l}3(21) \\
9(64) \\
2(14)\end{array}$ & $\begin{array}{c}38(61) \\
19(31) \\
5(8)\end{array}$ & 0.025 \\
\hline $\begin{array}{l}\text { Clinical symptoms, } n(\%) \\
\text { Diarrhea } \\
\text { Abdominal pain } \\
\text { Blood or mucous } \\
\text { Vomiting }\end{array}$ & $\begin{array}{l}17(100) \\
12(71) \\
9(53) \\
9(53)\end{array}$ & $\begin{array}{l}36(61) \\
18(31) \\
30(51) \\
7(12)\end{array}$ & $\begin{array}{c}0.002 \\
0.004 \\
0.879 \\
<0.001\end{array}$ & $\begin{array}{l}10(71) \\
10(71) \\
10(71) \\
9(64)\end{array}$ & $\begin{array}{l}43(69) \\
20(32) \\
29(47) \\
7(11)\end{array}$ & $\begin{array}{c}0.879 \\
0.013 \\
0.096 \\
<0.001\end{array}$ \\
\hline $\begin{array}{l}\text { Peak grade of diarrhea, } n(\%)^{\text {a }} \\
1 \\
2 \\
3\end{array}$ & $\begin{array}{l}4(24) \\
6(35) \\
7(41)\end{array}$ & $\begin{array}{l}15(42) \\
14(39) \\
7(19)\end{array}$ & 0.206 & $\begin{array}{l}3(30) \\
2(20) \\
5(50)\end{array}$ & $\begin{array}{c}16(37) \\
18(42) \\
9(21)\end{array}$ & 0.154 \\
\hline Duration of symptoms, median days (IQR) & $21(11-33)$ & $30(11-105)$ & 0.025 & $14(7-33)$ & $30(15-90)$ & 0.037 \\
\hline Hospitalization, $n(\%)$ & $13(76)$ & $22(37)$ & 0.006 & $14(100)$ & $21(34)$ & $<0.001$ \\
\hline Duration of hospitalization, median (IQR) & $8(7-16)$ & $5(3-12)$ & 0.161 & $8(5-15)$ & $6(3-11)$ & 0.421 \\
\hline CT scan imaging abnormality, $n(\%)^{\mathrm{b}}$ & $10(100)$ & $8(53)$ & 0.011 & $8(89)$ & $10(63)$ & 0.158 \\
\hline $\begin{array}{l}\text { Endoscopic presentation, } n(\%) \\
\text { Ulcer } \\
\text { Nonulcerative inflammation } \\
\text { Normal }\end{array}$ & $\begin{array}{l}5(29) \\
6(35) \\
6(35)\end{array}$ & $\begin{array}{l}14(24) \\
26(44) \\
19(32)\end{array}$ & 0.798 & $\begin{array}{l}7(50) \\
5(36) \\
2(14)\end{array}$ & $\begin{array}{l}12(19) \\
27(44) \\
23(37)\end{array}$ & 0.044 \\
\hline Received taxane after GI toxic effects, $n(\%)$ & $7(41)$ & $12(20)$ & 0.080 & $2(14)$ & $17(27)$ & 0.496 \\
\hline Recurrent GI symptoms, $n(\%)$ & $1(6)$ & $6(10)$ & 0.590 & $0(0)$ & $7(11)$ & 0.187 \\
\hline
\end{tabular}

fluids did not prevent the recurrence of colitis symptoms. The consequences of taxane-induced colitis were found to be severe, leading to treatment discontinuation, hospitalization, ICU admission, and even colon perforation.

Previous case reports of taxane-induced colitis had nonspecific histologic findings, including pseudomembranous colitis and ischemic colitis $[21,22]$. However, the small number of reported cases has made it difficult to fully characterize the effects of taxanes on the colon. In our study, the endoscopic findings of colitis were mostly nonulcerative inflammation or normal appearance, while only a minority of patients had mucosal ulcerations. The endoscopic features were comparable between symptomatic and asymptomatic patients. While most of the patients evaluated had nonspecific endoscopy findings, most were found to have signs of colitis on histology. Around 83\% of symptomatic and $78 \%$ of asymptomatic patients had evidence of active inflammation on histology, and the majority had evidence of chronicity. On the basis of these findings, we can conclude that while endoscopic findings may not be specific, a biopsy should be performed to determine the presence of chemotherapy-induced colitis. This was the main reason we studied only patients who had undergone endoscopic evaluation: to clarify the role of endoscopic and histologic evaluation. However, it remains a challenge to clearly delineate the specific triggering medication.
Our study is unique in that it compares colitis characteristics among patients who received different taxane agents. We found that nab-paclitaxel therapy was associated with more severe colitis, while paclitaxel therapy seemed to lead to a milder form. The duration from taxane treatment to colitis symptom onset was shortest for nab-paclitaxel therapy and longest for paclitaxel therapy. Nab-paclitaxel-induced colitis was associated with a $100 \%$ rate of hospitalization in our cohort, compared to only $34 \%$ among patients who developed paclitaxel-induced colitis. Interestingly, nab-paclitaxel is a solvent-free, albumin-bound formulation of paclitaxel developed to avoid toxicities associated with the cremophor solvent used in paclitaxel. However, the toxicities of cremophor were mostly hypersensitivity reactions, neutropenia, prolonged peripheral neuropathy and fluid retention [23]. In phase II and III trials, nab-paclitaxel therapy yielded fewer hypersensitivity reactions, but had a similar profile to that of paclitaxel for side effects such as neutropenia, neuropathy, alopecia and mild GI symptoms [10,24-27]. The fact that nab-paclitaxel seemed to be associated with more severe colitis in our cohort may be partially explained by its mechanism of action. Nab-paclitaxel is albumin-bound and utilizes the leaky vasculature of the tumor interstitium and albumin receptors to mediate drug transport across the microvasculature to reach high concentrations in the 
cancer cells [28]. The GI tract also contains albumin receptors, which may contribute to accumulation of nab-paclitaxel in the GI tract, causing more severe colitis symptoms [29]. Interestingly, adjuvant platinum-based therapy to taxane did not augment the level of severity of diarrhea/colitis or worsen the clinical outcomes in our cohort. However, this could be confounded by the limited sample size for subgroup analysis.

Notably, the ANC at the onset of taxane-induced colitis was recorded to help distinguish chemotherapy-induced colitis from neutropenic colitis, as cancer patients who receive chemotherapy are at high risk of neutropenia [30]. We observed a normal range of ANCs at the time of colitis presentation. This suggests that a temporary immunocompromised status is less likely to contribute to taxane-induced colitis.

We found that, although treatment of colitis with intravenous fluids and/or antibiotics reduced the duration of symptoms, these treatments did not prevent symptom recurrence. This observation could be explained by the fact that patients who received any type of GI symptom treatment had more severe colitis initially. Intravenous fluids can replenish fluids lost with diarrhea, while antibiotics have been shown to have some beneficial effect on colon inflammation, such as inflammatory bowel disease [31-33]. Presumably the alteration of the gut microbiome by the antibiotics could play a critical role in the colon's health. Exactly how the antibiotic treatment benefits this colitis condition and whether antibiotics should be given as a part of routine practice still require further clarification. Unlike patients with checkpoint-inhibitor-induced colitis, for which the main treatment is corticosteroids [34], only a few patients in our cohort received steroid therapy.

In recent years, colitis induced by cancer therapies, especially immune checkpoint inhibitors, has drawn the interest of gastroenterologists worldwide [35-39]. Some even argue that immune checkpoint-inhibitor-induced colitis should be recognized as a new inflammatory bowel disease entity [35,40-42]. A treatment algorithm was established for checkpoint-inhibitorinduced colitis [43-45], but not much is known regarding taxane-induced colitis. This rare event should be more closely followed, especially with the increasing use of chemotherapy and immunotherapy combinations $[46,47]$. For instance, in non-small cell lung cancer, the combination of atezolizumab, carboplatin, bevacizumab, and paclitaxel recently received approval from the US Food and Drug Agency for clinical use [48]. While the rate of grade 3 or higher diarrhea in the study of that drug combination was $1.3 \%$, the rate of grade $1-2$ diarrhea was $17.8 \%$. Thus, recognizing the colitis risk with taxanes will be more important when they are used with immunotherapy combinations in unselected patient populations (i.e. outside of clinical trials), in which the rates of side effects are expected to be higher.

Our study had several limitations. First, it was a retrospective review of electronic medical records, and details of the colitis symptoms and treatments could have been missed because of the conversion to an electronic medical record during the study period. Second, the sample size of this study was underpowered in the subgroup analyses. Third, this was a single-center study, and the common practice at our center may not represent the practice at other centers, especially since there are no standard treatment recommendations for this entity. Fourth, a selection

\section{Summary Box}

\section{What is already known:}

- Taxane therapy is effective for a number of malignancies

- Taxane therapy has been reported to be associated with gastrointestinal side effects

- Detailed characterization of the clinical, endoscopic and histopathological features of taxane therapy-related gastrointestinal toxicities is lacking

\section{What the new findings are:}

- Colitis is not a common adverse event of taxane-based chemotherapy, but it can have serious consequences, such as cancer treatment discontinuation, intensive care unit admission, and even colonic perforation

- Nab-paclitaxel therapy was associated with more serious forms of colitis in our cohort compared with the more commonly used taxanes

- Treatment of taxane-induced colitis with intravenous fluids and antibiotics shortened the duration of symptoms

bias likely resulted from the inclusion of only patients who underwent colonoscopy, since patients who require such evaluation usually have more severe GI symptoms, which could have underestimated the overall incidence of taxanerelated colitis in the larger cancer population. Lastly, many cases of colitis were diagnosed by biopsy, and the resulting delay in treatment may have led to a longer symptom duration and recurrence of symptoms.

To conclude, although colitis is not a common adverse event of taxane-based chemotherapy, it can have serious consequences. Taxane-induced colitis can lead to cancer treatment discontinuation, ICU admission, and even colonic perforation. Symptoms of taxane-induced colitis presented slowly and gradually in our cohort, mostly as bloody diarrhea and uncommonly as abdominal pain and nausea. Nabpaclitaxel therapy led to a more serious form of colitis in our cohort compared with the more commonly used taxanes. Although most patients had nonspecific endoscopic findings, significant and prevalent histologic inflammation prompted our attention to consider this evaluation tool to discern the presence of chemotherapy-induced colitis. Treatment with intravenous fluids and antibiotics shortened the duration of symptoms. Thus, these treatments should be encouraged once taxane-induced colitis is confirmed by endoscopy and/ or histology. Large-scale prospective studies are needed to investigate the appropriate treatment for this entity. 


\section{Acknowledgment}

Medical editing of this paper was provided by the Department of Scientific Publications at MD Anderson Cancer Center

\section{References}

1. Sparano JA, Zhao F, Martino S, et al. Long-term follow-up of the E1199 phase III trial evaluating the role of taxane and schedule in operable breast cancer. J Clin Oncol 2015;33:2353-2360.

2. Nowak AK, Wilcken NR, Stockler MR, Hamilton A, Ghersi D. Systematic review of taxane-containing versus nontaxane-containing regimens for adjuvant and neoadjuvant treatment of early breast cancer. Lancet Oncol 2004;5:372-380.

3. Kumar A, Hoskins PJ, Tinker AV. Dose-dense paclitaxel in advanced ovarian cancer. Clin Oncol (R Coll Radiol) 2015;27:40-47.

4. Jin Y, Sun Y, Shi X, et al. Meta-analysis to assess the efficacy and toxicity of docetaxel-based doublet compared with docetaxel alone for patients with advanced NSCLC who failed first-line treatment. Clin Ther 2014;36:1980-1990.

5. Fossella FV. Docetaxel for previously treated non-small-cell lung cancer. Oncology (Williston Park) 2002;16(6 Suppl 6):45-51.

6. He X, Wang J, Li Y. Efficacy and safety of docetaxel for advanced non-small-cell lung cancer: a meta-analysis of Phase III randomized controlled trials. Onco Targets Ther 2015;8:2023-2031.

7. Vermorken JB, Remenar E, van Herpen C, et al; EORTC 24971/TAX 323 Study Group. Cisplatin, fluorouracil, and docetaxel in unresectable head and neck cancer. $N$ Engl J Med 2007;357:1695-1704.

8. Wani MC, Taylor HL, Wall ME, Coggon P, McPhail AT. Plant antitumor agents. VI. The isolation and structure of taxol, a novel antileukemic and antitumor agent from Taxus brevifolia. J Am Chem Soc 1971;93:2325-2327.

9. Wall ME, Wani MC. Camptothecin and Taxol: Discovery to Clinic, Thirteenth Bruce F. Cain Memorial Award Lecture. Cancer Res 1995;55:753-760.

10. Mirtsching B, Cosgriff T, Harker G, Keaton M, Chidiac T, Min M. A phase II study of weekly nanoparticle albumin-bound paclitaxel with or without trastuzumab in metastatic breast cancer. Clin Breast Cancer 2011;11:121-128.

11. Schiff PB, Fant J, Horwitz SB. Promotion of microtubule assembly in vitro by taxol. Nature 1979;277:665-667.

12. Weaver BA. How Taxol/paclitaxel kills cancer cells. Mol Biol Cell 2014;25:2677-2681.

13. Guchelaar HJ, ten Napel CH, de Vries EG, Mulder NH. Clinical, toxicological and pharmaceutical aspects of the antineoplastic drug Taxol a review. Clin Oncol (R Coll Radiol) 1994;6:40-48.

14. Rowinsky EK, Cazenave LA, Donehower RC. Taxol: a novel investigational antimicrotubule agent. J Natl Cancer Inst 1990;82:1247-1259.

15. Tashiro M, Yoshikawa I, Kume K, Otsuki M. Ischemic colitis associated with paclitaxel and carboplatin chemotherapy. Am J Gastroenterol 2003;98:231-232.

16. Daniele B, Rossi GB, Losito S, Gridelli C, de Bellis M. Ischemic colitis associated with paclitaxel. J Clin Gastroenterol 2001;33:159-160.

17. Sodhi KS, Aiyappan SK, Singh G, Prakash M, Khandelwal N. Colitis and colonic perforation in a patient with breast carcinoma treated with taxane based chemotherapy. Indian J Cancer 2011;48:134-135.

18. Li Z, Ibrahim NK, Wathen JK, et al. Colitis in patients with breast carcinoma treated with taxane-based chemotherapy. Cancer 2004;101:1508-1513.
19. Charlson ME, Pompei P, Ales KL, MacKenzie CR. A new method of classifying prognostic comorbidity in longitudinal studies: development and validation. J Chronic Dis 1987;40:373-383.

20. Common Terminology Criteria for Adverse Events (CTCAE) v5.0. 2018. Available from: https://ctep.cancer.gov/protocoldevelopment/ electronic_applications/docs/CTCAE_v5_Quick_Reference_8.5x11. pdf [Accessed 01 November, 2019].

21. Hussein MA, Bird BR, O'Sullivan MJ, et al. Symptoms in cancer patients and an unusual tumor: Case 2. Docetaxel-related ischemic colitis. J Clin Oncol 2005;23:9424-9425.

22. Carrion AF, Hosein PJ, Cooper EM, Lopes G, Pelaez L, RochaLima CM. Severe colitis associated with docetaxel use: A report of four cases. World J Gastrointest Oncol 2010;2:390-394.

23. Vishnu P, Roy V. Safety and efficacy of nab-paclitaxel in the treatment of patients with breast cancer.. Breast Cancer (Auckl) 2011;5:53-65.

24. Ibrahim NK, Samuels B, Page R, et al. Multicenter phase II trial of ABI-007, an albumin-bound paclitaxel, in women with metastatic breast cancer. J Clin Oncol 2005;23:6019-6026.

25. Coleman RL, Brady WE, McMeekin DS, et al. A phase II evaluation of nanoparticle, albumin-bound (nab) paclitaxel in the treatment of recurrent or persistent platinum-resistant ovarian, fallopian tube, or primary peritoneal cancer: a Gynecologic Oncology Group study. Gynecol Oncol 2011;122:111-115.

26. Green MR, Manikhas GM, Orlov S, et al. Abraxane, a novel Cremophor-free, albumin-bound particle form of paclitaxel for the treatment of advanced non-small-cell lung cancer. Ann Oncol 2006; 17:1263-1268.

27. Gradishar WJ, Tjulandin S, Davidson N, et al. Phase III trial of nanoparticle albumin-bound paclitaxel compared with polyethylated castor oil-based paclitaxel in women with breast cancer. J Clin Oncol 2005;23:7794-7803.

28. Merlot AM, Kalinowski DS, Richardson DR. Unraveling the mysteries of serum albumin-more than just a serum protein. Front Physiol 2014;5:299.

29. Larsen MT, Kuhlmann M, Hvam ML, Howard KA. Albumin-based drug delivery: harnessing nature to cure disease. Mol Cell Ther 2016;4:3.

30. Lalami Y, Klastersky J. Impact of chemotherapy-induced neutropenia (CIN) and febrile neutropenia (FN) on cancer treatment outcomes: An overview about well-established and recently emerging clinical data. Crit Rev Oncol Hematol 2017;120:163-179.

31. Nitzan O, Elias M, Peretz A, Saliba W. Role of antibiotics for treatment of inflammatory bowel disease. World J Gastroenterol 2016;22:1078-1087.

32. Breton J, Kastl A, Hoffmann N, et al. Efficacy of combination antibiotic therapy for refractory pediatric inflammatory bowel disease. Inflamm Bowel Dis 2019;25:1586-1593.

33. Ledder O, Turner D. Antibiotics in IBD: still a role in the biological era? Inflamm Bowel Dis 2018;24:1676-1688.

34. Tian Y, Abu-Sbeih H, Wang Y. Immune checkpoint inhibitorsinduced colitis. Adv Exp Med Biol 2018;995:151-157.

35. Wang Y, Abu-Sbeih H, Mao E, et al. Endoscopic and histologic features of immune checkpoint inhibitor-related colitis. Inflamm Bowel Dis 2018;24:1695-1705.

36. Wang Y, Abu-Sbeih H, Mao E, et al. Immune-checkpoint inhibitor-induced diarrhea and colitis in patients with advanced malignancies: retrospective review at MD Anderson. J Immunother Cancer 2018;6:37.

37. Abu-Sbeih H, Ali FS, Alsaadi D, et al. Outcomes of vedolizumab therapy in patients with immune checkpoint inhibitor-induced colitis: a multi-center study. J Immunother Cancer 2018;6:142.

38. Wang Y, Wiesnoski DH, Helmink BA, et al. Fecal microbiota transplantation for refractory immune checkpoint inhibitorassociated colitis. Nat Med 2018;24:1804-1808.

39. Abu-Sbeih H, Ali FS, Qiao W, et al. Immune checkpoint inhibitor- 
induced colitis as a predictor of survival in metastatic melanoma. Cancer Immunol Immunother 2019;68:553-561.

40. Bertha M, Bellaguara E, Kuzel T, Hanauer S. Checkpoint inhibitorinduced colitis: a new type of inflammatory bowel disease. ACG Case Rep J 2017;4:e112.

41. Choi K, Abu-Sbeih H, Samdani R, et al. Can immune checkpoint inhibitors induce microscopic colitis or a brand new entity? Inflamm Bowel Dis 2018;25:385-393.

42. Abu-Sbeih H, Ali FS, Luo W, Qiao W, Raju GS, Wang Y. Importance of endoscopic and histological evaluation in the management of immune checkpoint inhibitor-induced colitis. J Immunother Cancer 2018;6:95.

43. Haanen J, Carbonnel F, Robert C, et al. Management of toxicities from immunotherapy: ESMO Clinical Practice Guidelines for diagnosis, treatment and follow-up. Ann Oncol 2017;28(Suppl_4):iv119-iv142.

44. Johnson DH, Zobniw CM, Trinh VA, et al. Infliximab associated with faster symptom resolution compared with corticosteroids alone for the management of immune-related enterocolitis. $J$ Immunother Cancer 2018;6:103.

45. Wang Y, Wiesnoski DH, Helmink BA, et al. Fecal microbiota transplantation for refractory immune checkpoint inhibitorassociated colitis. Nat Med 2018;24:1804-1808.

46. Socinski MA, Jotte RM, Cappuzzo F, et al; IMpower150 Study Group. Atezolizumab for first-line treatment of metastatic nonsquamous NSCLC. N Engl J Med 2018;378:2288-2301.

47. Gandhi L, Rodríguez-Abreu D, Gadgeel S, et al; KEYNOTE-189 Investigators. Pembrolizumab plus chemotherapy in metastatic non-small-cell lung cancer N Engl J Med 2018;378:2078-2092.

48. FDA approves atezolizumab with chemotherapy and bevacizumab for first-line treatment of metastaticnon-squamous NSCLC. Available from: https://www.fda.gov/Drugs/InformationOnDrugs/ ApprovedDrugs/ucm627874.htm [Accessed 01 November, 2019]. 


\section{Supplementary Tables}

Supplementary Table 1 Patient characteristics stratified by colitis treatment

\begin{tabular}{|c|c|c|c|}
\hline Covariate & Taxane monotherapy $n=32$ & Combination $^{\text {a }}$ therapy $n=44$ & $P$-value \\
\hline Peak grade of colitis, $n$ (\%) & & & 0.430 \\
\hline 1 & $13(41)$ & $13(30)$ & \\
\hline 2 & $16(50)$ & $23(52)$ & \\
\hline 3 & $3(9)$ & $8(18)$ & \\
\hline Peak grade of diarrhea, $n(\%)$ & & & 0.367 \\
\hline 1 & $6(26)$ & $13(43)$ & \\
\hline 2 & $11(48)$ & $9(30)$ & \\
\hline 3 & $6(26)$ & $8(27)$ & \\
\hline Hospitalization, $n(\%)$ & $12(38)$ & $23(52)$ & 0.149 \\
\hline ICU admission, $n(\%)$ & $2(6)$ & $5(11)$ & 0.367 \\
\hline Duration of hospitalization, median days (IQR) & $6(3.3-12.5)$ & $8(3-15)$ & 0.676 \\
\hline Endoscopic inflammation, $n(\%)$ & $20(63)$ & $31(71)$ & 0.621 \\
\hline Active inflammation on histology, $n(\%)$ & $27(90)$ & $36(84)$ & 0.510 \\
\hline Treatment, $n(\%)$ & $24(75)$ & $26(59)$ & 0.221 \\
\hline Immunosuppressants & $4(13)$ & $4(9)$ & 0.714 \\
\hline Antibiotic & $2(6)$ & $15(34)$ & 0.005 \\
\hline Antimotility agents & $13(41)$ & $5(11)$ & 0.005 \\
\hline IV fluid & $5(16)$ & $9(21)$ & 0.766 \\
\hline Octreotide and somatostatin & $0(0)$ & $2(5)$ & 0.506 \\
\hline Recurrent GI symptoms, $n(\%)$ & $2(6)$ & $5(11)$ & 0.692 \\
\hline
\end{tabular}

${ }^{\mathrm{a} C o m b i n a t i o n ~ t h e r a p y ~ i n c l u d e ~ t a x a n e ~ a n d ~ p l a t i n u m ~ b a s e d ~ m e d i c a t i o n ~}$

Radiotherapy administered: 18 in taxane monotherapy group, 15 in combination therapy group

$I C U$, intensive care unit; $I V$, intravenous

Supplementary Table 2 Effect of NSAID and smoking on endoscopy finding and clinical outcome of colitis

\begin{tabular}{lcccccc}
\hline & NSAID $n=41$ & No NSAID $n=35$ & $P$ & Smoking $n=37$ & No smoking $n=39$ & $P$ \\
\hline Endoscopy inflammation & $29(71)$ & $22(63)$ & 0.625 & $23(62)$ & $28(72)$ & $9(23)$ \\
Colon ulcerations & $12(29)$ & $7(20)$ & 0.430 & $10(27)$ & 0.466 \\
Complications of colitis & $1(2)$ & $0(0)$ & $>0.99$ & $1(3)$ & 0.793 \\
Hospitalization & $25(61)$ & $10(29)$ & 0.006 & $20(54)$ & 0.487 \\
ICU admission & $6(15)$ & $1(3)$ & 0.116 & $5(14)$ & $3(39)$ & $2(5)$ \\
Recurrent diarrhea & $4(10)$ & $3(9)$ & $>0.99$ & $3(8)$ & $4(10)$ & $>.250$ \\
\hline
\end{tabular}

ICU, intensive care unit; NSAID, nonsteroidal anti-inflammatory drug 
Supplementary Table 3 Detailed information regarding the antibiotics administered

\begin{tabular}{lc}
\hline Category of antibiotics & $n=17$ \\
\hline Metronidazole & 13 \\
Ciprofloxacin & 8 \\
\hline Piperacillin-Tazobactam & 5 \\
Vancomycin (iv and po) & 5 \\
\hline Amoxicillin/clavulanate & 2 \\
\hline Cefepime & 2 \\
\hline Linezolide & 2 \\
\hline Tigecycline & 1 \\
\hline Moxifloxacin & 1 \\
\hline Meropenem & 1 \\
\hline Levofloxacin & 1 \\
\hline Aztreonam & 1 \\
\hline
\end{tabular}

Combination therapy in 14 patients, monotherapy in 3 patients

$i v$, intravenous; po, per os 